\title{
A culture of control?
}

Lorraine Hawick $^{1}$, Alan Thomson ${ }^{2}$, Jennifer Cleland ${ }^{3}$

${ }^{1}$ Dr Lorraine Hawick, Clinical Lecturer. Institute of Education for Medical and Dental Education, School of Medicine, Medical Sciences and Nutrition, University of Aberdeen, Foresterhill, Aberdeen, AB25 2ZB

${ }^{2}$ Dr Alan R Thomson, Consultant Anaesthetist. Anaesthetic Department, Aberdeen Royal Infirmary, Foresterhill Road, Aberdeen. AB25 2ZN

${ }^{3}$ Professor Jennifer Cleland, John Simpson Chair of Medical Education. Institute of Education for Medical and Dental Education, School of Medicine, Medical Sciences and Nutrition, University of Aberdeen, Foresterhill, Aberdeen, AB25 2ZD

\section{Corresponding author:}

Lorraine Hawick

Clinical Lecturer

School of Medicine, Medical Sciences and Nutrition

Room 2:038, Polwarth Building

Foresterhill Campus

University of Aberdeen

Aberdeen

AB25 2ZD

Tel: 01224437731

Email: l.hawick@abdn.ac.uk 
In this edition, Zeeman and colleagues (1) report on a study which aimed to evaluate students' prediction of their use of academic time and to assess the same students' logged academic time. Students were asked to predict how much time they would spend on nine academic and other predefined activities during a typical weekday. Faculty were also asked to predict student time use.

We were struck by the underlying premise of this study - that time is a quantifiable, measurable and objective resource. This led us to consider four different aspects of students' academic time use. First, drawing on various political theorists (Giddens(2), Foucault(3) and Marx(4)), this particular research process and its desired outcome could be interpreted as obtaining data (from students) for making the work process (curriculum design) more efficient. (5) From the perspective that obtaining data is a form of surveillance, and surveillance is "a medium of power", (1: p.341) the authors have collected data which can then be used for disciplinary purposes; (3) that is, ensuring that students spend an appropriate number of hours on academic activities. Indeed, we were very interested in the fact that, although positioned as a student learning activity, 'all time-use exercise activities were required assignments embedded within required professional development coursework'. (1) Control is clearly apparent here - we wonder whether the students even had the option whether to take part in the process or not.

Such "workforce surveillance" $(5,6)$ aims to ensure that employees (in this case students) do not use work time as idle time, but as value generating activity (e.g., studying). Woe betide the student whose study time was not aligned with the independent study parameters of two hours independent work per hour of Faculty contact time, whose time on activities of daily living indicated less-than-optimal personal hygiene time or whose activities did not fit neatly into the pre-defined categories! 
The irony is that, as per earlier studies of workforce surveillance, (known) workplace and workforce surveillance leads to employees disciplining their own activities as a form of self-regulated behaviour and resisting attempts to be controlled. $(5,3)$ This was clear in the Zeeman et al study: the processes of surveillance and control were subverted by the students who reported that the time they anticipated using was indeed the time they used. Perhaps - knowingly or not - the students positioned themselves in this way to protect their existing temporal rhythms, by not giving faculty the ammunition to make changes, to impose new ways of working. We were left wondering - what is the next step: using CCTV to monitor if students' reported academic time use is accurate? This would fit with the arguments of some critical scholars who propose we are living in new Marxian times given the rise of state and consumer surveillance. $(4,7,8)$

Second, as alluded to earlier, time can be considered in two ways. The first is objective, in terms of its function in structuring and ordering everyday events and experiences (e.g., get up, wash, go to class, spend two hours on independent study for every hour of contact time). The second does not follow this objective 'clock time'. Rather time is viewed as a subjective and social experience. Broadly speaking, the literature on time from disciplines such as sociology, (9) anthropology, (10) and psychology (11) indicates that individuals experience and relate to time not as objective and measurable, but rather as "something that is full of meaning and is organized based on qualitative distinctions" (9: p.297) For example, an hour of study time may seem a lot at the beginning of term, but may seem all too short the day before an exam. An hour of academic activity may drag, whereas an hour with friends is likely to pass in a flash. Perceptions of time are influenced by individual differences (e.g., background, ability) and socio-cultural (e.g., culture/country) factors. (13)

This brings us to our third point. The concept of two hours of independent work per hour of Faculty contact time is both objective and subjective. This so-called "Carnegie rule" is a means of structure and a social construct, one which was developed by those overseeing and regulating education over 
a century ago. (14) Yet where is the evidence that a strict time policy of one plus two is an effective medium for learning? Studies in education highlight that time spent studying does not appear to equate in a linear way to better grades. (15-17) Moreover, where does this time-based approach to education fit with more contemporary outcomes and competency-focused approaches, new sources of information and ways of learning?

While curriculum planners may view the delivery of teaching primarily through a time-shaped lens we would caution against adopting a similar perspective of student learning. Students' use of academic time will, and should, vary considerably depending on their circumstances and context. A more productive and learner-centred approach might be to consider how students' qualitative use of time relates to academic outcomes and whether faculty can influence this positively. In short, how can we best equip our students to engage effectively in independent learning?

Finally, while we sense there is a disconnection between the past and the present in medical education, we can also see that different stakeholders may have different perspectives on change. For example, the motive behind student credit hours was a business one, to document workload and institutional productivity. Medical schools positioned in a neoliberal, international marketplace may see increasing productivity as very attractive. If more time can be found in the day to study and/or study time can be made more efficient, then students can be processed through the education system more quickly, degree programmes could be shorter, and more cohorts can be processed through the system, thus increasing the productivity of the educational organisation. (18) From our position as teachers, the idea of more student throughput and increased workload fills us with horror. For students, why rush through a course? Time at university is important for many reasons other than gaining credits - developing friendships, learning to look after oneself, self-and timemanagement, and so on. 
In conclusion, we make a plea to shift from quantity measures such as time spent in independent study to considering quality measures through students' engagement with the process of study. Time cannot be measured purely by minutes and seconds. 


\section{References}

1. Zeeman J, Kang I, Angelo T. Assessing student academic time use: Assumptions, predictions, and realities.le. Med Educ. 2018;53(3):xx - xx.

2. Giddens A. The Nation-State and Violence. Cambridge: Polity Press; 1995.

3. Foucault M. Discipline and punish : the birth of the prison. London: Penguin Books; 1979.

4. Hobsbawm EJ. How to change the world : tales of Marx and Marxism. London: Little Brown; 2012.

5. Taylor FW. The principles of scientific management. New York: Dover Publications; 2003.

6. Fuchs C. Political Economy and Surveillance Theory. Crit Sociol. 2013;39(5):671-87.

7. Ball K, Webster $\mathrm{F}$. The Intensification of surveillance: crime, terrorism and warfare in the information era. London: Pluto Press; 2003.

8. Eagleton T. Why Marx Was Right. London, UK: Yale University Press; 2011.

9. Adam B. Time and Social Theory. Vol. 20, Contemporary Sociology. Oxford: Polity Press; 1991.

10. Gell A. The anthropology of time : cultural constructions of temporal maps and images. Oxford: Berg; 1992.

11. McGrath JE, Tschan F. Temporal matters in social psychology: examining the role of time in the lives of groups and individuals. Washington: American Psychological Association; 2004.

12. Güell P, Yopo M. The subjective texture of time. An exploratory and empirical approach to time perspectives in Chile. Time Soc. 2016;25(2):295-319.

13. Zerubavel E. Time maps : collective memory and the social shape of the past. Chicago: University of Chicago Press; 2003.

14. Silva E, White T, Toch T. The Carnegie Unit: A Century-Old Standard in a Changing Education Landscape. [Internet]. Carnegie Foundation for the Advancement of Teaching. Stanford, CA: Carnegie Foundation for the Advancement of Teaching.; 2015. Available from: http://www.carnegiefoundation.org

15. Barbarick KA, Ippolito JA. Does the Number of Hours Studied Affect Exam Performance ? J Nat 
Resour life Sci Educ. 2003;32:32-5.

16. Hammonds F, Mariano G. Student Test Grades in College: A Study of Possible Predictors. Int J Teach Learn High Educ. 2015;27(1):114-8.

17. Wilson SM. Measuring the Quantity and Quality of the K-12 STEM Teacher Pipeline Author. Menlo Park, CA; 2016.

18. Au W. Teaching under the new Taylorism: high-stakes testing and the standardization of the 21 st century curriculum. J Curric Stud. 2011;43(1):25-45. 